\title{
Rare Case of Isolated Dural Marginal Zone Lymphoma
}

\section{Introduction}

Lymphomatous involvement of the central nervous system (CNS) may manifest either as the sole area of disease (i.e., primary CNS lymphoma [PCNSL]) or more commonly as part of a systemic disease.

PCNSL accounts for $<1 \%$ of all non-Hodgkin's lymphoma cases and approximately $4 \%$ of newly diagnosed primary CNS tumors. ${ }^{[1]}$ Most cases of PCNSL are aggressive, especially in the settings of underlying immunocompromised state. ${ }^{[2]}$ Dural lymphomas (DLs) are a rare subtype of PCNSL that involve the dura mater without infiltration to the brain parenchyma. Low-grade lymphomas, especially marginal zone subtype, constitute majority of DLs. Herein, we report a case of primary dural marginal zone lymphoma (MZL).

\section{Case Report}

A 65-year-old woman presented with a history of insidious onset, continuous, dull-aching, holocranial headache for 4 years. She also complained of a swelling on the right side of the scalp for 1 year. She had no history of vomiting, blurring of vision, seizures, or history of swelling elsewhere over the body. Her father was diagnosed with a hematological malignancy and mother had throat cancer (details of histopathology and treatment were not available).

On examination, her vitals were stable with an ECOG performance status of 1 . Local examination revealed a diffuse, hard, immobile, $5 \mathrm{~cm} \times 5-\mathrm{cm}$ scalp lesion continuous with the underlying bone. There were no cranial nerves deficits. Ophthalmological evaluation yielded no significant abnormalities. Sensory, motor, and cerebellar functions were normal. There were no neurocutaneous markers.

\section{Question 1}

Clinical differential diagnosis of such a presentation?

\section{Answer}

(1) Plasmacytoma; (2) Langerhans cell histiocytosis; (3) lymphoma; (4) benign bone tumor.

Magnetic resonance imaging (MRI) brain revealed a well-defined extra-axial $\mathrm{T} 1$ iso and mildly $\mathrm{T} 2$ hyperintense heterogenous lesion in the right parietal area, crossing midline with intra and extracranial components [Figure 1]. There was thickening and widening of the overlying bone. The lesion was $6.3 \mathrm{~cm} \times 3.2 \mathrm{~cm}$ in the greatest dimensions with intense postcontrast enhancement. It was suspicious of an en-plaque meningioma/lymphoma. Screening MRI of the whole spine showed no significant lesions elsewhere. Cerebrospinal fluid evaluation was unremarkable.

She underwent a right fronto-temporo-parietal craniotomy and decompression of the lesion. Her postoperative period was complicated with new-onset hemiparesis. MRI was suggestive of cortical vein thrombosis. She was managed conservatively. She recovered within 3 months and on last follow-up, she had a minimal residual deficit (power in the left extremities 4/5).

\section{Question 2}

Which is the most common type of lymphoma affecting the CNS?

Answer

Diffuse large B-cell lymphoma (DLBCL) (up to 90\% of cases).

The histopathology of the operated specimen revealed atypical lymphoid infiltration of the dura [Figure 2]. They were arranged in sheets with intervening thick fibrous septa. On immunohistochemistry, tumor cells expressed leukocyte common antigen, CD20, and BCL 2. They were negative for BCL 6, CD5, CD23, Cyclin D1, Tdt, and CD10. CD21 was highlighting the follicular dendritic cell meshwork. Ki 67 index was low (15\%-20\%) [Figure 2].

The patient was diagnosed and staged as primary extra-nodal (dural) MZL. MRI brain plus spine done postsurgery was not suggestive of any residual disease. A contrast-enhanced computed tomography of the neck/thorax/abdomen/pelvis showed no other sites of involvement. Bone marrow biopsy did not show any lymphomatous involvement.

\section{Question 3}

Incidence of isolated CNS involvement with MZL?

Answer

Extranodal MZL of the (CNS EMZBL) is a rare disease. Seventy cases have been reported in literature worldwide till date ${ }^{[3]}$ and to the best of our knowledge, this is the first case report from our country.

As the patient had no evidence of systemic involvement, she was started on adjuvant external beam radiotherapy (RT). She received 24 Gy in 12 fractions. At the last follow-up, i.e., 12 months after initial presentation, she had no clinical evidence of the disease.

\section{Discussion}

MZL represents a group of indolent lymphomas that arise from postgerminal center marginal zone B cells. They 


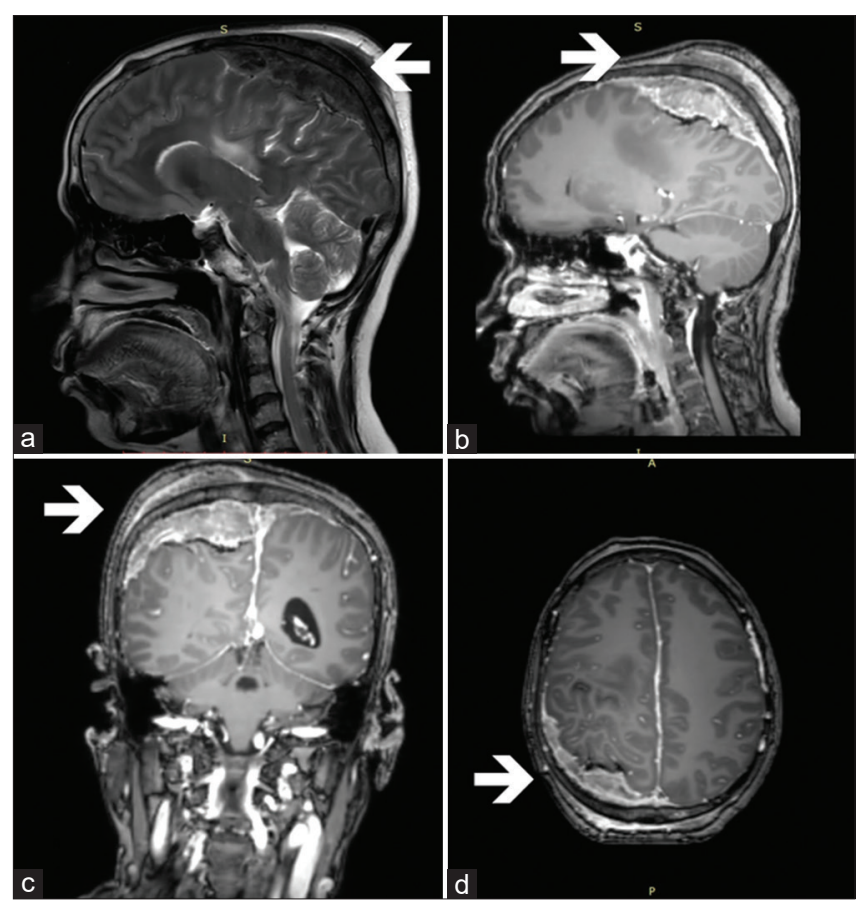

Figure 1: Preoperative magnetic resonance imaging of the patient showing a relatively well-defined mildly $\mathrm{T} 2$ hyperintense heterogenous extra-axial lesion. (a) With intracranial and extracranial components. The lesion shows intense postcontrast enhancement as visualized in the sagittal (b), coronal (c), and axial (d) planes. The intracranial component is crossing the midline; the underlying brain parenchyma appears indented and scalloped by the lesion

comprise approximately $3 \%$ of all lymphoid neoplasms..$^{[4,5]}$ They may be further divided into nodal, extranodal, and splenic MZL as per the World Health Organization classification. ${ }^{[6]}$ Extranodal MZL which accounts for up to $70 \%{ }^{[7]}$ arises most commonly in the stomach. Other common sites are salivary glands, lung, small bowel, thyroid, ocular adnexa, and skin. ${ }^{[8]}$ They tend to remain localized to the tissue of origin for long periods of time, though it has the potential for systemic spread and transformation to an aggressive B-cell lymphoma.

DL is a rare type of PCNSL arising from the dura mater. A retrospective review of 26 patients by de la Fuente et al..$^{[9]}$ from Memorial Sloan Kettering Cancer Center and University of Miami represents the largest published case series. Among the forty patients included in an international study on low-grade PCNSL by Jahnke et al., ${ }^{[10]}$ isolated meningeal involvement was observed in two patients.

The median age of diagnosis is around the fifth to sixth decade. There is a female preponderance (around 70\%). ${ }^{[3,9]}$ This is in contrast to parenchymal PCNSL, which is more common in men. The most common presenting symptoms are headaches $(40 \%)$ and seizures. ${ }^{[11]}$

Neuroimaging frequently identifies single or multiple, diffusely enhancing, extra-axial lesions with a dural tail. Frontal lobe followed by temporal lobe represents the most common sites. In contrast, DLBCL presenting as

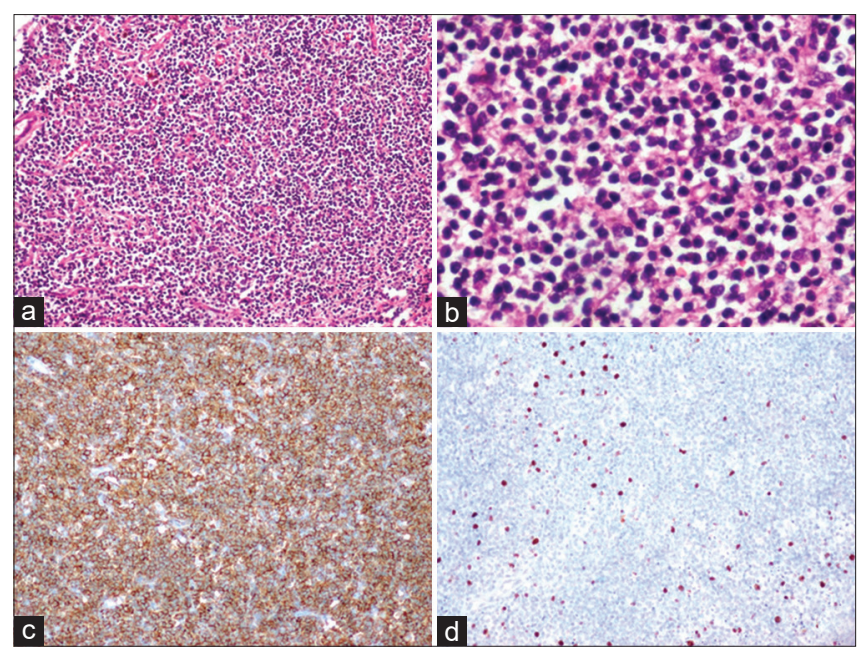

Figure 2: Histopathology of the resected specimen. (a) Low-power view showing sheets of lymphoid cells $(H$ and $E, \times 100)$. (b) High-power view showing neoplastic lymphoid cells, with many of them having clear cytoplasm (H and E, $\times 400$ ). (c) Immunoperoxidase staining with neoplastic lymphoid cells expressing CD20 (horseradish peroxidase [HRP] polymer method, $\times 100)$. (d) Immunoperoxidase staining with neoplastic lymphoid cells expressing low Ki67 (HRP polymer method, ×100)

PCNSL is usually located in hemispheric white or deep gray matter and unlikely to present as a dural lesion. Meningioma is a close radiological differential diagnosis. Lower enhancement of lesion in comparison to the dural tail, lower apparent diffusion coefficient values, and the underlying vasogenic edema favor MZL over meningioma.

Pathological evaluation of these lymphomas shows diffuse infiltration and adherence to sclerotic meningeal tissue. Immunophenotypically, pan-B cell markers, i.e., CD20, CD22, CD19, as well as CD79a and PAX-5 are positive. The tumor cells are usually positive for BCL-2. They are frequently negative for CD10, BCL-6, and EBER; CD5 can be positive in a subset of cases. $\mathrm{Ki}-67$ proliferation index will be characteristically low in contrast to aggressive lymphomas.

Extranodal MZL limited to a single site is usually treated with local treatment such as surgery followed by focal RT. ${ }^{[9]}$ The optimal radiation dose is less well defined, although relatively low doses of RT produce excellent results in patients with a single disease site. The role of intrathecal chemotherapy and benefit of adjuvant systemic therapy remain unclear.

\section{Conclusion}

Primary CNS MZL is a rare entity whose clinical presentation may be confused with meningioma. Their relatively good prognosis is in contrast to the more common primary aggressive B-cell CNS lymphomas.

\section{Declaration of patient consent}

The authors certify that they have obtained all appropriate patient consent forms. In the form the patient(s) has/have given his/her/their consent for his/her/their images and 
other clinical information to be reported in the journal. The patients understand that their names and initials will not be published and due efforts will be made to conceal their identity, but anonymity cannot be guaranteed.

\section{Financial support and sponsorship}

Nil.

\section{Conflicts of interest}

There are no conflicts of interest.

\section{Suresh Babu', Syed Adil Hassan', Chennagiri S Premalata ${ }^{2}$, D Lokanatha ${ }^{1}$, Linu Abraham Jacob', NK Lokesh', HA Rudresha ${ }^{1}, K_{L}$ Rajeev $^{1}$, Smitha Saldanha ${ }^{1}$, Antony George Francis Thottian ${ }^{1}$}

${ }^{1}$ Department of Medical Oncology, Kidwai Memorial Institute of Oncology, Bengaluru, Karnataka, India, '2Department of Pathology, Kidwai Memorial Institute of Oncology, Bengaluru, Karnataka, India

Address for correspondence: Dr. MC Suresh Babu, Department of Medical Oncology, Kidwai Memorial Institute of Oncology, Bengaluru - 560 029, Karnataka, India. E-mail: sureshbabu_mc@yahoo.co.in

Submitted: 08-Jan-2020 Accepted in Revised Form: 13-Feb-2020 Published: 24-Apr-2020

\section{References}

1. Villano JL, Koshy M, Shaikh H, Dolecek TA, McCarthy BJ. Age, gender, and racial differences in incidence and survival in primary CNS lymphoma. Br J Cancer 2011;105:1414-8.

2. O'Neill BP, Illig JJ. Primary central nervous system lymphoma. Mayo Clin Proc 1989;64:1005-20.

3. Ayanambakkam A, Ibrahimi S, Bilal K, Cherry MA. Extranodal marginal zone lymphoma of the central nervous system. Clin Lymphoma Myeloma Leuk 2018;18:34-7.e8.

4. Novak U, Basso K, Pasqualucci L, Dalla-Favera R, Bhagat G. Genomic analysis of non-splenic marginal zone lymphomas (MZL) indicates similarities between nodal and extranodal MZL and supports their derivation from memory B-cells. Br J Haematol 2011;155:362-5.
5. Morton LM, Wang SS, Devesa SS, Hartge P, Weisenburger DD, Linet MS. Lymphoma incidence patterns by WHO subtype in the United States, 1992-2001. Blood 2006;107:265-76.

6. Campo E, Swerdlow SH, Harris NL, Pileri S, Stein H, Jaffe ES. The 2008 WHO classification of lymphoid neoplasms and beyond: Evolving concepts and practical applications. Blood 2011;117:5019-32.

7. Zinzani PL. The many faces of marginal zone lymphoma. Hematology Am Soc Hematol Educ Program 2012;2012:426-32.

8. Khalil MO, Morton LM, Devesa SS, Check DP, Curtis RE, Weisenburger DD, et al. Incidence of marginal zone lymphoma in the United States, 2001-2009 with a focus on primary anatomic site. Br J Haematol 2014;165:67-77.

9. de la Fuente MI, Haggiagi A, Moul A, Young RJ, Sidani C, Markoe A, et al. Marginal zone dural lymphoma: The Memorial Sloan Kettering Cancer Center and University of Miami experiences. Leuk Lymphoma 2017;58:882-8.

10. Jahnke K, Korfel A, O’Neill BP, Blay JY, Abrey LE, Martus P, et al. International study on low-grade primary central nervous system lymphoma. Ann Neurol 2006;59:755-62.

11. Iwamoto FM, DeAngelis LM, Abrey LE. Primary dural lymphomas: A clinicopathologic study of treatment and outcome in eight patients. Neurology 2006;66:1763-5.

This is an open access journal, and articles are distributed under the terms of the Creative Commons Attribution-NonCommercial-ShareAlike 4.0 License, which allows others to remix, tweak, and build upon the work non-commercially, as long as appropriate credit is given and the new creations are licensed under the identical terms.

\begin{tabular}{|l|l|}
\hline \multicolumn{2}{|c|}{ Access this article online } \\
\hline Quick Response Code: & Website: \\
& www.ijmpo.org \\
\cline { 2 - 2 } & DOI: \\
\hline
\end{tabular}

How to cite this article: Babu MC, Hassan SA, Premalata CS, Lokanatha D, Jacob LA, Lokesh NK, et al. Rare case of isolated dural marginal zone lymphoma. Indian J Med Paediatr Oncol 2020;41:61-3. 